\title{
ANTERIOR LAMELLAR RECESSION FOR TREATMENT OF CICATRITIAL ENTROPION WITH OR WITHOUT BLEPHAROPLASTY
}

By

\author{
Abubakr Mohammad Farid Abulnaga, Ahmed Sobhy, Mohammed Eid \\ Abd El-Salam, Mohammed Abdulmunsif Mousay \\ Department of Ophthalmology, Faculty of Medicine, Al-Azhar University \\ *Corresponding Author: Mohammed abdulmunsif mousay, \\ E-mail: okaly1989@gmail.com , Phone: 00201093422845- 00218918588415,
}

Address: Dannha, Libya

\begin{abstract}
Background: Entropion is an inward rotation of the eyelid margin. It is one of the most common lid malposition encountered in clinical practice. There are four types of entropion: congenital, cicatricial, involutional and acute spastic. The pathophysiology of each of these types is different, and so is the treatment.

Objectives: To compare between anterior lamellar recession with blepharoplasty and without blepharoplasty.

Patients and Methods: Twenty cases of cicatricial entropion by anterior lamellar recession with age range age from 35-75 years were included in this study which was performed at Al-Azhar University Hospitals divided into two equal groups: Group (A): with upper eyelid cicatricial entropion had an anterior lamellar recession by gray line split technique and Group (B) with upper eyelid cicatricial entropion had an anterior lamellar recession by gray line split technique and blepharoplasty.

Result: In Group A, we had one case of recurrence observed after 3 months (10\%) while in group B no cases of recurrence observed after 3 months $(0 \%)$, In group A, success rate was $90 \%$, and final aesthetic outcome was $30 \%$, while in Group B success rate was $100 \%$, and final aesthetic outcome was $80 \%$, group B showed less post-operative complication than group A.

Conclusions: Combining the procedure of anterior lamellar recession with grey line split technique with blepharoplasty in surgical correction of upper eye lid cicatricial entropion has excellent both functional and aesthetic outcome, and a higher success rate with minimal complication than anterior lamellar reposition only, as simultaneous correction of associated lid laxity and dermatochalisis maximize the efficacy of ALR and enhance the postoperative cosmesis.
\end{abstract}

\section{INTRODUCTION}

Cicatritial entropion is an internal rotation of eye lid due to vertical tarsoconjunctival contracture leading to keratinized eyelid margin and irritation of the globe (Cantor and Rapuano, 2016).

Cicatricial entropion results from a differential horizontal shortening of the posterior lamella of the eyelid in relation to the anterior lamella. Chronic inflammation such as meibomianitis, blepharo-conjunctivitis and trachoma can lead to lid margin keratinization, trichiasis, or dis-trichiasis (Rashad et al., 2018). 
One of the most common causes of cicatritial entropion in many countries is trachoma, trachoma is chronic keratoconjunctivitis caused by Chlamydia trachomatis infection, The World Health Organization (WHO) appreciation that 21.4 million people have active trachoma of which7.2 million suffer from blinding trichiasis while 1.2 million people are actually blind (Smith et al., 2011).

Treatment of cicatricial entropion should always include medical control of the underlying pathologic condition when present. Surgical management poses a challenge of lysing the scar tissue responsible for margin malposition without the corrective surgery inciting additional inflammation. Surgical technique depends on the severity of disease and etiology of symptoms (Iyengar and Dresner, 2012).

If there is mild disease with symptoms from lashes abrading the corneal surface, skin resection may be enough to rotate the margin. Follicle excision is achieved by splitting the lamella posterior to the lashes and excising the lashes with Westcott scissors. The base of the lash follicles is then cauterized to prevent regrow therapy can be offered, for severe cicatricial disease, the posterior lamella must be lengthened, while releasing scar tissue and lid retractors. In these instances, the posterior lid retractors can be weakened by recession or lysis with a spacer (Kakizaki et al., 2009).

The first one who described anterior lamellar recession is Welsh in 1969 with grey line splitting suture repositioning for correcting cicatricial entropion. Some other published techniques have added a lid crease incision with GLS to recess the levator (Nowinski, 2011).

Anterior lamellar recession (ALR) is a well-known conventional surgical method for the correction of a mild to moderate upper lid entropion. It consists of splitting skin and orbicularis oculi muscle from tarsus and conjunctiva, recessing the anterior lamella and leaving the exposed tarsus bare, Interlamellar separation can be performed through gray line approach, eyelid crease approach, or both Few studies are available that present the effect of this procedure through upper lid crease incision in upper eye lid cicatricial entropion (Owji and Tehrani, 2013).

Blepharoplasty is the surgical removal of the redundant eyelid tissues (skin, orbicularis muscle, and orbital fat), which can be for functional or cosmetic purposes. It is a useful procedure, not only isolated but also in conjunction with other procedures, such as browpexy ptosis repair (Dos Santos and Nassaralla, 2009).

The present work aimed to compare between anterior lamellar recession with blepharoplasty and without blepharoplasty.

\section{PATIENTS AND METHODS}

Twenty cases of cicatricial entropion by anterior lamellar recession with age range age from 35-75 years were included in this study which was performed at AlAzhar University Hospitals and divided into two equal groups:

Group (A) lids with upper eyelid cicatricial entropion had an anterior lamellar recession by gray line split technique, and Group (B) lids with upper eyelid cicatricial entropion had an anterior 
lamellar recession by gray line split technique and blepharoplasty.

\section{Inclusion criteria:}

Patients with cicatricial entropion and not treated with other types of surgery, age from 35-75 years .Consents for surgery and photography was obtained from every patient as well as the approval of institutional ethical committee .All patients were undergoing full ophthalmological examination including: visual acuity, refraction, fundus examination, intra ocular pressure measurement (IOP), Slit lamp examination, the position and direction of the lashes.

Preoperative preparation: The patients were asked about any previous upper eye lid surgery especially entropion surgery and systemic diseases as hypertension, cardiac diseases, diabetes mellitus, blood disorders and coagulopathies. Patients were instructed to discontinue all blood thinners as oral anticoagulants aspirin, antiplatelets (plavix) or vitamin E, full laboratory investigations as complete blood count, prothrombin time, prothrombin concentration, international normalized ratio, serum glutamic oxaloacetic transaminase, serum glutamic pyruvic transaminase, blood urea, creatinine and viral screen were done.

All operations were done under local anesthesia. Topical anesthesia was installed in both eyes. The lid was then infiltrated in the submuscular space by mixture of Mepivacaine HCL (2\%) with a 1:20,000 dilution of Levonoradrenaline (Mepecaine-L). It was given along the whole length of the upper lid and in the lateral canthal angle, and only Mepivacaine HCL (2\%) in cardiac or hypertensive patients.

\section{Statistical analysis:}

Recorded data were analyzed using the statistical package for social sciences, version 20.0 (SPSS Inc., Chicago, Illinois, USA). Qualitative data were expressed as frequency and percentage and compared by Fisher exact test. $\mathrm{P}$ value $\leq 0.05$ was considered significant.

\section{RESULTS}

This study showed that combining the procedure of anterior lamellar recession with grey line split technique with blepharoplasty in surgical correction of upper eye lid cicatricial entropion has excellent both functional and aesthetic outcome, and a higher success rate with minimal complication than anterior lamellar reposition only, as simultaneous correction of associated lid laxity and dermatochalasis maximize the efficacy of
ALR and enhance the postoperative cosmesis.

In group $\mathrm{A}$, there was one case of recurrence after 3 months (10\%), while in group B no cases of recurrence were observed after 3 months $(0 \%)$. Group A success rate was $90 \%$, and final aesthetic outcome was 30\%, while in group B success rate was $100 \%$. And final aesthetic outcome was $80 \%$ (Table 1). 


\section{ABUBAKR MOHAMMAD FARID ABULNAGA et al.,}

Table (1): Comparison between two groups as regard success

\begin{tabular}{|c|c|c|c|}
\hline $\begin{array}{ll}\text { Results } & \text { Groups } \\
\end{array}$ & Group A & Group B & p-value \\
\hline Success & $9(90 \%)$ & $10(100.0 \%)$ & $>0.05$ \\
\hline Failed & $1(10.0 \%)$ & $0(0.0 \%)$ & $>0.05$ \\
\hline
\end{tabular}

Group B showed less post-operative complication than group A (Table 2) In order to achieve lid crease symmetry in single eyelid entropion trichiasis, simple blepharoplasty in the other eye ordered to the patient.

Table (2): Complication of two groups

\begin{tabular}{|l|c|c|c|}
\hline Complication & Groups & Group B & p-value \\
\hline Wound infection & $0(0.0 \%)$ & $0(0.0 \%)$ & $>0.05$ \\
\hline Lid edema & $8(80 \%)$ & $10(100 \%)$ & $>0.05$ \\
\hline Necrosis at wound & $0(0 \%)$ & $2(20 \%)$ & $>0.05$ \\
\hline Lagophthalmos & $1(10.0 \%)$ & $0(0.0 \%)$ & $>0.05$ \\
\hline Recurrence after 3 months & $1(10.0 \%)$ & $0(0.0 \%)$ & $>0.05$ \\
\hline
\end{tabular}

\section{DISCUSSION}

Ahmed and Abdelbaky (2015), in a very large study, found that all patients had signs of trachoma. ALR with grey line split was performed with also no crease incision. They reported by the end of 6 months follow up, $14.9 \%$ of lids showed recurrence, while $66.1 \%$ were completely cured and $19 \%$ had partial success. Comparing the results of our study in (group A) with the results of the previous study, the difference due to the prolonged follow-up period and the number of cases in the previous study.

Ross et al, (2011), in their study of upper cicatricial entropion management, made their ALR technique with opening the septum and expose the levator aponeurosis. The levator was dissected and recessed; the lateral horn was released to eliminate all superior traction. Advancement of the posterior lamella then was made. Anatomical success of ALR in the study was $98 \%$ and $17 \%$ had recurrence of trichiasis. In this study, the result was close to our study in group A, but the difference was addition of levator recess, (success rate $90 \%$ ).

Rashad et al., (2018) anterior lamellar recession technique (ALR) with grey line split (GLS) technique. Group B: Ten lids had an anterior lamellar recession with GLS technique was $70 \%$, patient satisfaction was $60 \%$, and final aesthetic outcome was in $30 \%$ excellent, $30 \%$ had fair and $40 \%$ had poor results. This study is like our study in terms of the number of cases and the duration of follow-up, but there was a slight difference in the success rate of the operation. In our study success rate was $90 \%$ in this study was $70 \%$.

Aghai et al. (2016) combined ALR with blepharoblasty and supratarsal fixation in management of upper eyelid cicatricial entropion without lagophthalmos. This study differs slightly than our study regarded blepharoplasty in terms of the number of cases and length of the follow-up period in addition to the use of the process supra tarsal fixation to the 
cases, which led to a difference in the results.

\section{CONCLUSION}

Combining the procedure of anterior lamellar recession with grey line split technique with blepharoplasty in surgical correction of upper eye lid cicatricial entropion has excellent both functional and aesthetic outcome and a higher success rate with minimal complication than anterior lamellar reposition only, as simultaneous correction of associated lid laxity and dermatochalisis maximize the efficacy of ALR and enhance the postoperative cosmesis.

\section{LIMITATIONS}

This study finding needs further assessment on big series.

\section{CONFLICT OF INTEREST DISCLOSURE STATEMENT}

Authors declare that there was no any financial or personal conflict of interest.

\section{REFERENCES}

1. Aghai, G. H., Gordiz, A., Falavarjani, K. G. and Kashkouli, M. B. (2016): Anterior lamellar recession, blepharoplasty, and supratarsal fixation for cicatricial upper eyelid entropion without lagophthalmos. Eye, 30(4): 627-631.

2. Ahmed, R. A. and Abdelbaky, S. H. (2015): Short term outcome of anterior lamellar reposition in treating trachomatous trichiasis. Journal of Ophthalmology: 7 pages.

3. Cantor LB and Rapuano CJ (2016): Periocularmalpositions and involutional changes. IN;Basic and Clinical Science Course: orbit, eyelids and lacrimal system. American Academy of Ophthalmology, 7 (11): 230-282.

4. Dos Santos LH and Nassaralla BA (2009): Upper blepharoplasty; IN, Garg A, El-
Toukhy E, Nassaralla BA, Oculoplasty and reconstructive surgery made easy; 1 st ed; pbl Jaypee Brothers, New Delhi, , 12; 209-215.

5. Iyengar SS and Dresner SC. (2012): Entropion. In Black EH, Nesi FA, Calvano CJ, Gladstone GJ, Levine MR editors. Smith and Nesi's Ophthalmic Plastic and Reconstructive Surgery. 3rd ed, New York (USA): P 311-315.

6. Kakizaki, H., Malhotra, R., Madge, S. N and Selva, D. (2009): Lower eyelid anatomy: an update. Annals of Plastic Surgery, 63(3): 344-351.

7. Nowinski TS. (2011): Entropion. In: Tse DT, editor. Color Atlas of Oculoplastic Surgery. 2nd ed. Pbl Philadelphia: Lippincott Williams \& Wilkins, P44-53.

8. Owji, N and Tehrani, J. (2013): Anterior lamellar recession in the management of the trachomatous cicatricial entropion of the upper eyelids: Outcomes and indications. Asian Journal of Ophthalmology, 13(2): 4247.

9. Rashad, S. M., Abd Elhamid, M. A. and El-nenaey, S. H. (2018): A comparative study between anterior lamellar repositioning and anterior lamellar repositioning with blepharoplasty in management of upper eyelid entropion trichiasis. The Egyptian Journal of Hospital Medicine, 72(4): 44074412.

10. Ross, A. H., Cannon, P. S., Selva, D. and Malhotra, R. (2011): Management of upper eyelid cicatricial entropion. Clinical \& Experimental Ophthalmology, 39(6): 526536.

11. Smith JL, Haddad D, Polack S, HardingEsch, E M, Hooper P J, Mabey DC and Brooker S. (2011): Mapping the Global Distribution of Trachoma: Why an Updated Atlas Is Needed. PLOS Neglected Tropical Diseases, 5(6): 1-4. 
عملية إرجاع الطبقة الأمامية لعلاج إنقلاب حافة الجفن

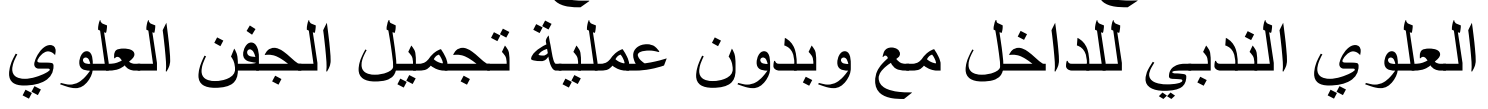

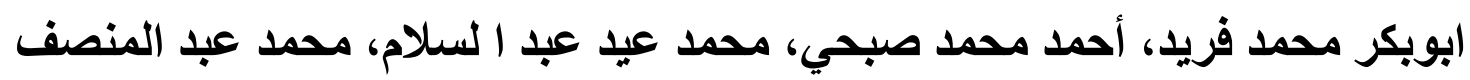

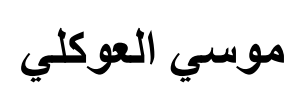

قسم طب وجراحة العيون، كلية الطب، جامعة الأزهر، القاهرة

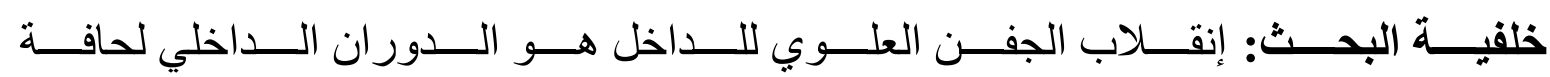

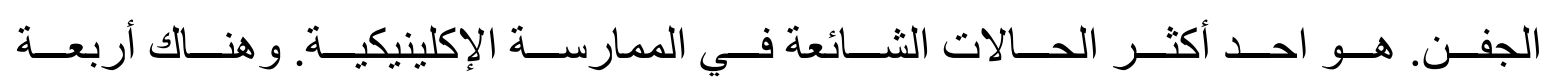

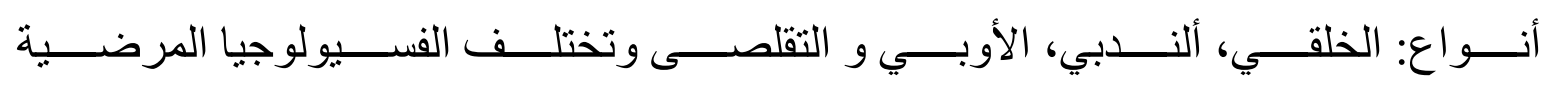

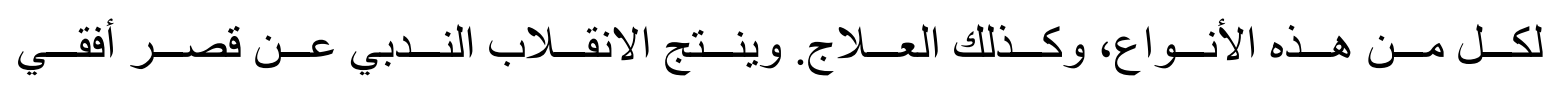

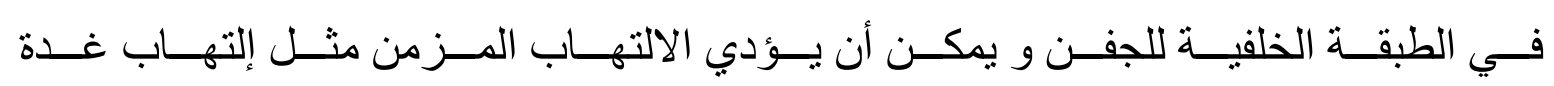

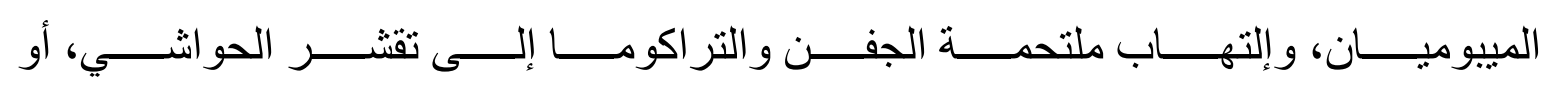

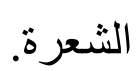

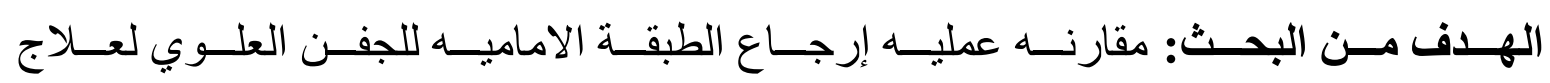
انقلاب حافة الجفن ألندبي للاخل مع وبله وبدون عمليه تقويم الجفن العلوي.

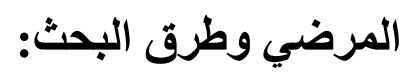

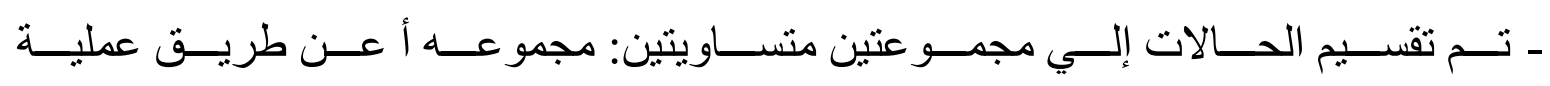

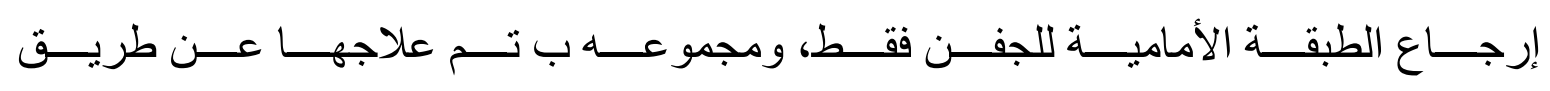
إرجاع الطبقة الأمامية مصاحبة لها عملية تقويم الجفن.

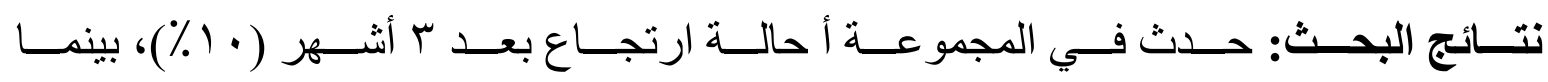

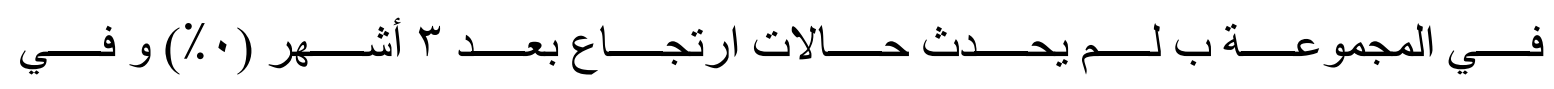

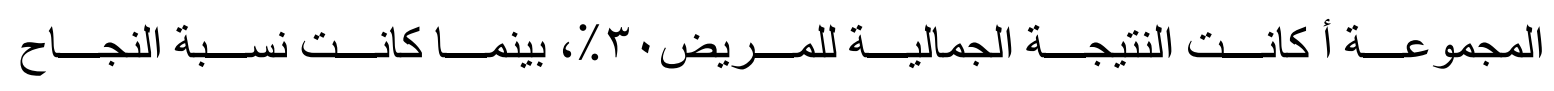

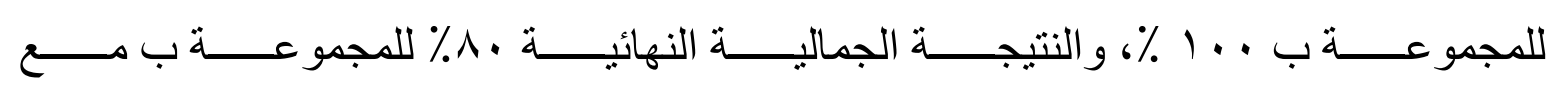

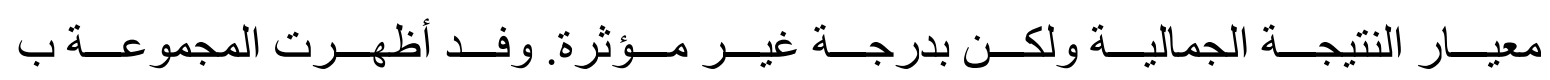

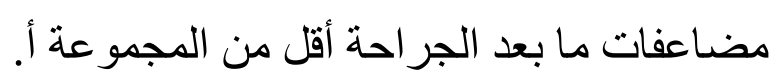




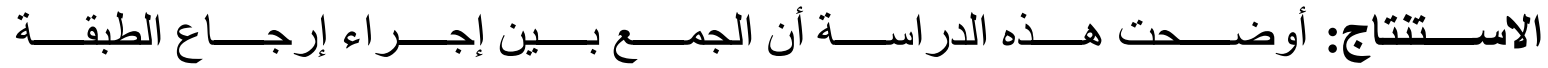

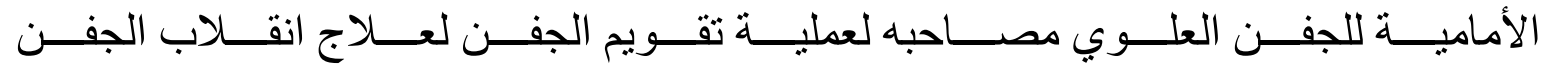

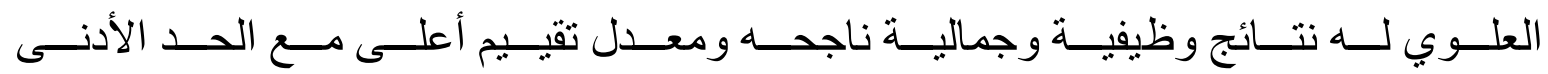

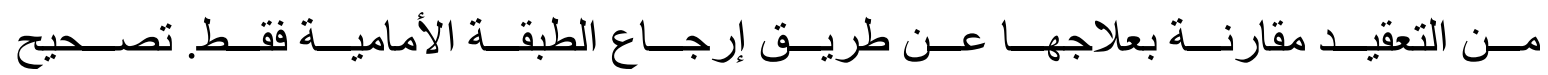

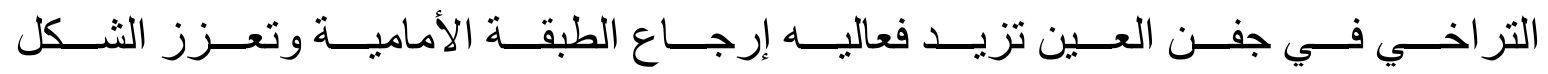
الجمالي بعد العملية الجر احية.

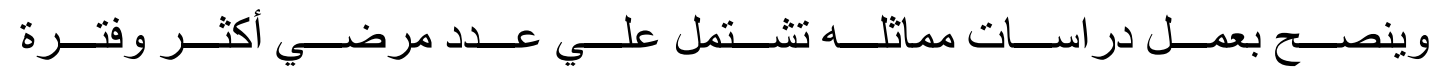
متابعه أطول للحصول علي نتائج أكثر دقه يمكن مقارنتها بالأبحاث المماثلة. 